\title{
BMJ Global Heath What is the value of palliative care provision in low-resource settings?
}

\author{
R Eleanor Anderson, ${ }^{1}$ Liz Grant ${ }^{2}$
}

To cite: Anderson RE, Grant $L$. What is the value of palliative care provision in low-resource settings?. BMJ Global Health 2017;2: e000139. doi:10.1136/ bmjgh-2016-000139

Received 26 July 2016 Accepted 3 November 2016

\footnotetext{
${ }^{1}$ Department of Emergency Medicine, Yale University School of Medicine, New Haven, Connecticut, USA ${ }^{2}$ Global Health Academy, University of Edinburgh, FRCPE, Edinburgh, UK
}

Correspondence to Dr R Eleanor Anderson; rachel.anderson@yale.edu
Palliative care is the active improvement in quality of life and relief of suffering for patients with incurable disease. ${ }^{1}$ Despite being recognised as a human right by the WHO ${ }^{1}$ the United Nations Committee on Economic, Social and Cultural Rights ${ }^{2}$ and the International Covenant for Economic, Social and Cultural Rights, ${ }^{3}{ }^{4}$ there are significant disparities in the worldwide provision of palliative care services for individuals with life-limiting illnesses. Of the 40 million people globally in need of palliative care, just $14 \%$ receive it, most of whom are adults and children in high-income countries (HICs). ${ }^{5} 6$ For the millions of individuals who die without palliative care, largely in low-income countries, end of life is typically marked by pain and suffering. This is due in part to the unavailability of oral analgesia ${ }^{7-10}$ but also more generally, to the fragility of health systems in low-resource settings. ${ }^{11}$ Particular barriers to the integration of palliative care in low-resource settings include lack of awareness by policymakers, health professionals and the public, of what palliative care is and the benefits it can offer patients and health systems. Additional barriers include cultural and social beliefs about death and dying, misconceptions that palliative care is only for patients with cancer, for those in their last days or weeks of life, and finally, the misconception that improving access to opioid analgesia could lead to increased substance abuse.

Cost of illness (COI) represents the total economic burden of a disease on society and is comprised of direct and indirect costs. Direct costs measure the resources used to treat illness (staff time, radiotherapy, chemotherapy, advanced imaging) while indirect costs usually measure lost productivity (the patient or family member taking time off of work or school). ${ }^{12}$ In HIC, dramatic increases in COI are common as the incurable disease progresses. In these settings, palliative care offers a resource-sparing alternative while simultaneously improving quality of life. ${ }^{13-17}$ Due in large part to this

\section{Summary box}

Palliative care is a human right, yet there are significant disparities in the worldwide provision of palliative care services for individuals with lifelimiting illness. Of the 40 million people globally in need of palliative care, just $14 \%$ receive it, largely in high-income countries.

- While proven to be 'cost-effective' in highincome settings based on principles of cost avoidance, the costs of illness for incurable disease in low-resource settings is largely unknown.

- The critical absence of palliative care services in low-resource settings results in significant costs being absorbed by the individual, family and local community. This results in intractable, devastating and perpetuating financial losses that are passed on to future generations and function as a catalyst in the poverty cycle while stunting local economic growth.

- In considering the direct, indirect and broader societal costs of incurable disease in lowresource countries, palliative care should be considered as a poverty-reduction strategy.

empirical evidence and the established costeffectiveness of palliative care in some HIC, the provision of palliative care in these locations has continued to increase over the past several decades. $^{18}$

Far less well understood is the COI of incurable diseases in low-resource settings. The authors have worked in palliative care in low-income and middle-income countries (LMICs) over the past 20 years. LG established one of the first rural hospital-based palliative care services in Kenya at Chogoria Hospital in the 1990s, and has led many research programmes on integration of palliative care into health systems in sub-Saharan Africa. REA is a Global Health fellow studying the value of global palliative care as a poverty reduction strategy.

Fragile health systems lack the safety nets of health insurance schemes, social support programmes and critically, palliative care services for patients with incurable disease. This 
results in tremendous costs of care that are inevitably absorbed by the individual, family and local community. For example, in a cohort of patients with cancer in Ethiopia, we found that reported medical costs, including medications, treatments and travel to health facilities, necessitated the sale of livestock, homes, wedding gold, as well as pulling children from school as the fees became unaffordable. In studies conducted in Malawi, Kenya, Rwanda, Uganda and Zambia, we identified that families prioritised the immediate need to seek for cures for their ill family member over saving funds for future household costs. The reluctance of clinical staff to break bad news about illness progression and prognosis contributed to this prioritisation of a search for a cure.

We have observed staggering direct and indirect costs of care for incurable disease in LMIC, which ultimately result in intractable, devastating and perpetuating financial losses that are passed on to future generations. Examples of direct costs include out-of-pocket expenses for medical visits, procedures, purchase of medications and transportation, any of which individually may be greater than a monthly salary. Homes, livestock, wedding gold and other important assets are often sold to pay for the direct costs of medical care. Understandably, the sale of these assets may cause a family struggling with poverty to slip into destitution. ${ }^{19}$

Indirect costs are harder to measure but comprise a significant burden of the cost of care for patients, their families and local communities. Common sources are missed wages from the patient who is too ill to work and often a second lost wage from the family member staying with the patient to provide care. Other indirect costs include a reduction in future earning potential due to the sale of assets such as livestock and farmland, to cope with direct costs, and lost opportunities for young people who are pulled out of school at a young age to care for ill adults or because school fees become unaffordable due to medical expenses. These factors have a negative impact not just on family wealth but also on the local economy. ${ }^{20}$

In small-scale economies, material wealth strongly predicts the wealth of offspring via intergenerational wealth transfer. Ultimately, when parents lose their wealth to medical costs, future generations are gravely affected: small-scale economies lack the potential for important individual earnings over a lifetime-the most significant form of wealth is inherited. ${ }^{21}$

The poverty cycle is a phenomenon by which impoverished families remain impoverished for three or more generations because they lack the resources necessary to exit the cycle. This is most often because they have used these resources to pay for expenses such as a death or illness. The lack of financial resources parallels a lack of other capital, such as educational and social connections, which in turn pushes the family even further into poverty. ${ }^{22}$ This has been shown to be true for chronic disease in LMICs, where the constant care and treatment required, and the length of illness (years rather than days) reduces the patient and families' capacity to purchase adequate drugs, or to earn money working.

Indeed, similarities exist between the chronic disease economic model and that for incurable disease: chronic disease simultaneously destroys the internal family resources and stunts local economic growth. ${ }^{4}$ The WHO has conceded that "existing knowledge underestimates the implications of chronic diseases for poverty and the potential that chronic disease prevention and health promotion have for alleviating poverty in low and middle income countries." ${ }^{23}$ They conclude that investment in chronic disease prevention programmes is essential to reduce poverty. We propose that investing in palliative care is just as essential to reducing poverty in LMICs. Similar to chronic disease, patients with incurable disease also face substantial costs, and the lack of access to palliative care services in these settings functions as a catalyst in the poverty cycle.

Global cancer care is perhaps the best example of a rigorous health economic model adapted and applied to LMICs. ${ }^{24}$ Strategies such as prevention, screening, capacity building and treatment form the cornerstones. Similarly rigorous economic models for palliative care delivery in LMICs are lacking, with most models from HICs where palliative care has been shown to be costeffective based on the principle of cost avoidance (avoiding expensive, non-beneficial therapies at end of life). Yet this model fails in low-resource settings where the alternative is no care. The potential benefit palliative care can offer patients, their children, grandchildren and local economy lies in mitigation of the costs of illness and suffering, rather than avoidance of costs of expensive treatment. ${ }^{25}$ On a societal level, palliative care can serve as a health system expander in offering patients with incurable disease the possibility of care within their homes, thereby reserving hospital-based care, with its limited resource of nurses, doctors and supplies for patients with potentially reversible illness.

Hand-in-hand with the lack of economic models for sustainable and cost-effective delivery of palliative care is buy-in from leading international global health institutions. The African Palliative Care Association is actively working to increase palliative care delivery and address the deficiency in regional and national palliative care policies. ${ }^{26}$ However, until palliative care is globally recognised as a sustainable, cost-effective intervention, it will not be recognised as a priority goal, and will continue to be underdeveloped and underfunded in the face of escalating need.

Though many LMICs have inverted pyramids with significant numbers of young people, there are also many nations with rising numbers of elderly who are living longer than ever. Non-communicable diseases, including cancer, are rising fastest in low-resource settings. ${ }^{27}$ Chronic disease, incurable disease and disability have become a reality for millions, and there has never been a more opportune time to invest in planning and development strategies to help care for them. 
Through the tireless efforts of many visionaries working to strengthen palliative care and the 2014 World Health Assembly Resolution there has been an increase in palliative care services, yet need far outweighs supply, and supply still remains too heavily dependent on external funding rather than integrated health sector expenditure. It is difficult to think about putting an actual economic value on the relief of human suffering. Yet this financial estimate is necessary to ultimately promote the expansion and longevity of palliative care services in LMICs. Demonstrating the economic value of palliative care in LMICs, through the development of a health economic model for delivery, is key to sustainability. This in turn is crucial to guiding healthcare policy and gaining momentum for increasing government-sponsored and locally run palliative care services. Our group is actively engaging health economists with international palliative care providers and consultants to construct this model. We believe that it is more costly not to have palliative care in low-resource settings, and that when palliative care services are incorporated into the health system, they can be delivered for minimal financial cost but enormous physical, emotional and social benefit per patient. Therefore, coordinated, international funding should focus on the widespread development and integration of palliative care services within local health systems, securing this human right for all.

\section{Handling editor Seye Abimbola.}

Contributors REA and LG have both contributed to the conception and design of this manuscript and to drafting and revising it critically for important intellectual content. They have both given final approval of the version to be published.

Competing interests None declared.

Provenance and peer review Not commissioned; externally peer reviewed.

Data sharing statement No additional data are available.

Open Access This is an Open Access article distributed in accordance with the Creative Commons Attribution Non Commercial (CC BY-NC 4.0) license, which permits others to distribute, remix, adapt, build upon this work noncommercially, and license their derivative works on different terms, provided the original work is properly cited and the use is non-commercial. See: http:// creativecommons.org/licenses/by-nc/4.0/

\section{REFERENCES}

1. World Health Organization Definition of Palliative Care. http://www. who.int/cancer/palliative/definition/en/ (accessed 29 Jan 2016).

2. Committee on Economic, Social and Cultural Rights. General comment no.14. Twenty- second session. Geneva, April 25 May 12, 2000.

3. Brennan F. Palliative care as an international human right. $J$ Pain Symptom Manage 2007;33:494-9.
4. Gwyther L, Brennan F, Harding R. Advancing palliative care as a human right. J Pain Symptom Manag 2009;38:767.

5. World Health Organization Palliative Care Factsheet. http://www.who. int/mediacentre/factsheets/fs402/en/ (accessed 28 Jan 2016).

6. World Health Organization Global Atlas of Palliative Care at the End of Life. http://www.who.int/cancer/publications/palliative-care-atlas/en/ (downloaded 28 January 2016).

7. Logie D, Leng M. Africans die in pain because of fears of opiate addiction. BMJ 2007;335:685.

8. Stjernswärd J. Instituting palliative care in developing countries-an urgently needed and achievable goal. J Pain Palliat Care Pharmacother 2003;17:3.

9. Hartwig K, Dean M, Hartwig K, et al. Where there is no morphine: the challenge and hope of palliative care delivery in Tanzania. Afr J Prim Health Care Fam Med 2014;6:549.

10. Seya MJ, Gelders SF, Achara OU, et al. A first comparison between the consumption of and the need for opioid analgesics at country, regional, and global levels. J Pain Palliat Care Pharmacother 2011;25:6-18.

11. Kim J-Y, Farmer P, Porter M. Redefining global health-care delivery. Lancet 2013;382:1060-9.

12. U.S. Health Policy Gateway. http://ushealthpolicygateway.com/ health-policy-intelligence-sources/f-health-policy-methods/ cost-of-illness-measurement/ (accessed 21 Oct 2016).

13. Smith T, Cassel B. Cost and non-clinical outcomes of palliative care. J Pain Symptom Manag 2009;38:32.

14. Pyenson B, Connor S, Fitch K, et al. Medicare cost in matched hospice and non-hospice cohorts. J Pain Symptom Manag 2004;28:200.

15. Felder $\mathrm{S}$, Meier $\mathrm{M}$, Schmitt $\mathrm{H}$, et al. Health care expenditure in the last months of life. J Health Econ 2000;19:679.

16. Zimmermann C, Riechelmann R, Krzyzanowska M, et al. Effectiveness of specialized palliative care: a systematic review. JAMA 2008;299:1698-709.

17. Brumley R, Enguidanos $\mathrm{S}$, Jamison $\mathrm{P}$, et al. Increased satisfaction with care and lower costs: results of a randomized trial of in-home palliative care. J Am Geriatr Soc 2007;55:993-1000.

18. Taylor D, Ostermann J, Van Houtven C, et al. What length of hospice use maximizes reduction in medical expenditures near death in the US Medicare program? Soc Sci and Med 2007;65:1466-78.

19. Krishna A. One illness away: why people become poor and how they escape poverty. New York (NY) and Oxford: Oxford University Press, 2011.

20. World Health Organization. Chronic disease and health promotion. http://www.who.int/chp/chronic_disease_report/part2_ch2/en/index7. html (accessed 2 Feb 2016).

21. Borgerhoff Mulder M, Bowles S, Hertz T, et al. Intergenerational wealth transmission and the dynamics of inequality in small-scale societies. Science 2009;326:682-8.

22. Payne RK. A framework for understanding poverty. 4th edn. Highlands, TX: Aha! Process, 2005.

23. World Health Organization. Chronic disease and health promotion. http://www.who.int/chp/chronic_disease_report/part2_ch2/en/index5. $\mathrm{html}$ (accessed 7 Oct 2016).

24. Gelband H, Sankaranarayanan R, Gauvreau C. Costs, affordability, and feasibility of an essential package of cancer control interventions in low-income and middle-income countries: key messages from Disease Control Priorities, 3rd edition. Lancet 2016;387:2133-44.

25. Salins N, Ramanjulu R, Patra L, et al. Integration of early specialist palliative care in cancer care and patient related outcomes: a critical review of evidence. Indian J Palliat Care 2016;22:252.

26. Luyirika E, Namisango E, Garanganga E, et al. Best practices in developing a national palliative care policy in resource limited settings: lessons from five African countries. Ecancermedicalscience 2016;10:652.

27. World Health Organization. Global Status Report on Non-Communicable Disease. http://www.who.int/nmh/publications/ ncd_report_full_en.pdf (accessed 21 Oct 2016). 